\title{
Role of ghrelin in fertilization, early embryo development, and implantation periods
}

\author{
Eugenia Mercedes Luque, Pedro Javier Torres, Nicolás de Loredo, Laura María Vincenti, \\ Graciela Stutz, María Emilia Santillán, Rubén Daniel Ruiz, Marta Fiol de Cuneo and \\ Ana Carolina Martini
}

Facultad de Ciencias Médicas, Instituto de Fisiología, Universidad Nacional de Córdoba, Santa Rosa 1085, X5000ESU Córdoba, Argentina

Correspondence should be addressed to A C Martini; Email: acmartini2000@yahoo.com

\begin{abstract}
In order to clarify the physiological role of ghrelin in gestation, we evaluated the effects of administration of exogenous ghrelin ( 2 or $4 \mathrm{nmol} /$ animal per day) or its antagonist ( $6 \mathrm{nmol} /$ animal per day of (D-Lys $\mathrm{s}_{3}$ GHRP6) on fertilization, early embryo development, and implantation periods in mice. Three experiments were performed, treating female mice with ghrelin or its antagonist: i) starting from 1 week before copulation to $12 \mathrm{~h}$ after copulation, mice were killed at day 18 of gestation; ii) since ovulation induction until $80 \mathrm{~h}$ later, when we retrieved the embryos from oviducts/uterus, and iii) starting from days 3 to 7 of gestation (peri-implantation), mice were killed at day 18. In experiments 1 and 3, the antagonist and/or the highest dose of ghrelin significantly increased the percentage of atrophied fetuses and that of females exhibiting this finding or a higher amount of corpora lutea compared with fetuses (nCL/nF) (experiment 3 : higher $\mathrm{nCL} / \mathrm{nF}$-atrophied fetuses: ghrelin 4, 71.4-71.4\% and antagonist, 75.0-62.5\% vs ghrelin 2, 46.2-15.4\% and control, 10-0.0\%; $n=7-13$ females/group; $P<0.01$ ). In experiment 2, the antagonist diminished the fertilization rate, and both, ghrelin and the antagonist, delayed embryo development (blastocysts: ghrelin 2, 62.5\%; ghrelin 4, 50.6\%; and antagonist, $61.0 \%$ vs control $78.4 \% ; n=82-102$ embryos/treatment; $\boldsymbol{P}<\mathbf{0 . 0 0 0 1})$. In experiment 3, additionally, ghrelin $(4 \mathrm{nmol} / \mathrm{day})$ and the antagonist significantly diminished the weight gain of fetuses and dams during pregnancy. Our results indicate that not only hyperghrelinemia but also the inhibition of the endogenous ghrelin effects exerts negative effects on the fertilization, implantation, and embryo/fetal development periods, supporting the hypothesis that ghrelin (in 'adequate' concentrations) has a physiological role in early gestational events.

Reproduction (2014) 148 159-167
\end{abstract}

\section{Introduction}

Ghrelin was originally identified in 1999 as the endogenous ligand of the growth hormone secretagogue receptor (GHSR1a; Kojima et al. 1999, 2001, Barreiro \& Tena-Sempere 2004, Fernández-Fernández et al. 2005). This substance is a 28-amino acid peptide, mainly secreted by the stomach and the hypothalamus. Although it essentially stimulates $\mathrm{GH}$ secretion and food intake, several studies have linked ghrelin to the reproductive physiology, mainly with the hypothalamic-hypophysealgonadal axis modulation (Kojima et al. 1999, 2001, Barreiro et al. 2002, Kawamura et al. 2003, FernándezFernández et al. 2006, García et al. 2007, Zhang et al. 2007, Tena-Sempere 2008a,b). Moreover, as plasma ghrelin concentrations dramatically increase during fasting or undernourishment (Kojima \& Kangawa 2005), this peptide has been proposed as an inhibitory signal for reproductive physiology and/or behavior during food scarcity periods (Fernández-Fernández et al. 2006,
Tena-Sempere 2008a,b), especially in females (Schneider 2004, Bertoldi et al. 2011).

Nevertheless, it is well known that ghrelin plasma level in mothers and fetuses increases during pregnancy in several mammalian species, suggesting that this peptide exerts some physiological roles in gestation. Nonetheless, there is still consensus neither about the stage of gestation in which ghrelin peaks (Gualillo et al. 2001, Fernández-Fernández et al. 2004, Shibata et al. 2004, Fuglsang et al. 2005, Govoni et al. 2007, Harrison et al. 2007, Palik et al. 2007) nor about its origin, with the placenta, corpora lutea, decidual endometrium, and/or fetal pancreas postulated as possible candidates (Gualillo et al. 2001, Caminos et al. 2003, Tanaka et al. 2003, Harrison et al. 2007). Moreover, as GHSR1a has been detected in mammalian placentae, endometria, and fallopian tubes (Gaytán et al. 2005, Harrison et al. 2007), it has been proposed that ghrelin might be one of the numerous peptides that regulate embryo implantation (Tanaka et al. 2003). Concordantly, in 
humans, in vitro experiments have demonstrated a decidualization-stimulating effect of ghrelin upon endometrial stromal cells in cultures (Tanaka et al. 2003). Finally, the ghrelin receptor has been identified in mammalian oocytes and embryos (Kawamura et al. 2003, Du et al. 2010), and ghrelin secretion has been linked to early embryo development. In fact, while some authors have claimed that this peptide has deleterious effects on the progress of mice embryo to blastocyst (Kawamura et al. 2003), other authors have demonstrated that it has stimulatory dose-dependent effects in sheep or pigs (Wang et al. 2007, Zhang et al. 2007).

Given the above-mentioned data, it is evident that although ghrelin is supposed to physiologically participate in early gestational events, there is a lack of knowledge about this presumable role, due to fragmentary evidences mostly obtained from in vitro designs. Therefore, the objective of this study is to investigate, by means of an in vivo approach, the effects of exogenous ghrelin administration (2 or $4 \mathrm{nmol} / \mathrm{animal}$ per day) or endogenous ghrelin inhibition (by $6 \mathrm{nmol} / \mathrm{animal}$ per day of (D-Lys $3_{3}$ GHRP6) on fertilization, early embryo development, and implantation periods in pre/gestating mice. For these purposes, three experiments were performed treating female mice with two doses of ghrelin or an antagonist: i) starting from 1 week before copulation to $12 \mathrm{~h}$ after copulation (gestation day 1 ), mice were killed at day 18 of gestation; ii) starting from ovulation induction to $80 \mathrm{~h}$ after ovulation, when we retrieved the embryos from oviducts and uterus; and 3) starting from days 3 to 7 of gestation (peri-implantation period), mice were killed at day 18 .

\section{Materials and methods}

\section{Animals}

Experiments were conducted in accordance with the Guide for the Care and Use of Laboratory Animals from the Medicine School of the Cordoba National University (UNC-RHCS 674/09). This Animal Ethical Committee approved the protocols used in this study.

We used adult female (60-80 days) inbred Albino Swiss mice $(\mathrm{N}: \mathrm{NIH})$ maintained on a $14 \mathrm{~h}$ light:10 h darkness cycle at $22 \pm 2{ }^{\circ} \mathrm{C}$ with water provision ad libitum. In order to avoid an increase in the body weight associated with possible orexigenic/anorexigenic effects of ghrelin or its antagonist, treated females received the same amount of food (Grupo Pilar-Gepsa, Cordoba, Argentina) as that consumed by control females at the same gestational period. Nevertheless, it is important to remark that, in previous experiments, we determined that the doses of ghrelin or its antagonist used in this study do not significantly modify daily food intake (PJ Torres, E M Luque \& A C Martini 2013, unpublished observations).

\section{Chemicals}

Ghrelin (Pi-Proteomics, Huntsville, AL, USA) and its antagonist, (D-Lys ${ }_{3}$ GHRP6 (Sigma-Aldrich), were both dissolved in isotonic solution $(0.9 \% \mathrm{CINa}$ solution) and injected subcutaneously, administering twice a day half the daily dose (at 0900 and $1700 \mathrm{~h}$ ). Control animals received the vehicle in the same regimen. The doses of ghrelin used in this study were selected based on its ability to increase $\mathrm{GH}$ secretion from a dose-response curve performed previously and published by our group (Bertoldi et al. 2011). Furthermore, similar doses were used by other authors, with comparable results in $\mathrm{GH}$ secretion (Wei et al. 2006, Sun et al. 2007). Concordantly, the selected dose of the antagonist had been previously demonstrated to inhibit the effects of endogenous hyperghrelinemia or exogenously administered ghrelin, which makes this option an effective ghrelin antagonist protocol (Bertoldi et al. 2011).

\section{Experimental groups}

All the experiments were performed on female mice subjected to one of the following treatments:

i) ghrelin 2: administration of $2 \mathrm{nmol} / \mathrm{animal}$ per day of ghrelin dissolved in $0.2 \mathrm{ml}$ isotonic solution.

ii) Ghrelin 4: administration of $4 \mathrm{nmol} /$ animal per day of ghrelin dissolved in $0.2 \mathrm{ml}$ isotonic solution.

iii) Ant: administration of $6 \mathrm{nmol} / \mathrm{animal}$ per day of (D-Lys 3 )GHRP6 (ghrelin antagonist) dissolved in $0.2 \mathrm{ml}$ isotonic solution.

iv) Control: administration of $0.2 \mathrm{ml}$ isotonic solution/ animal per day.

\section{Experiment 1}

In order to evaluate the role of ghrelin in the peri-fertilization period, we injected ghrelin or its antagonist into adult female mice starting from 1 week before the copulation confirmation day, inclusive. By the afternoon of the seventh day of treatment, a male mouse was introduced into the cage in which the female was housed, and evidences of copulation were evaluated every morning from this day onwards. All experimental females were receptive to males within the first 3 days, which implies that ghrelin and the antagonist were injected at a time period ranging from 7 to 9 days before copulation.

The day that copulation was confirmed was considered as day 1 of gestation. Females were killed on day 18 by cervical dislocation, in order to obtain ovaries and gravid uterus and to quantify the number of corpora lutea $(\mathrm{nCL})$, litter size, viable pups' weight, atrophied fetuses, and the $\mathrm{nCL} /$ number of fetuses $(\mathrm{nF})$. In previous studies, we considered the $\mathrm{nCL}$ as a sign of ovulation index and we have also considered that a higher $\mathrm{nCL} / \mathrm{nF}$, depending on the treatment period, may reflect alterations in reproductive processes such as fertilization, embryo development, and/or implantation (Puechagut et al. 2012).

\section{Experiment 2}

With the objective to evaluate the role of ghrelin in early embryo development, adult females were injected with ghrelin or the antagonist starting from the day of pharmacologically induced ovulation (with $5 \mathrm{IU}$ pregnant mares' serum and, 
$48 \mathrm{~h}$ later, $10 \mathrm{IU}$ human chorionic gonadotropin (hCG)) to the third day of pregnancy. By the afternoon of the hCG administration, male mice were introduced into the cages in which females were housed and copulation was confirmed the subsequent morning. After 2 days ( $80 \mathrm{~h}$ after the estimated ovulation time), females were killed in order to obtain reproductive organs and to quantify the fertilization rate and embryo development.

\section{Experiment 3}

In order to evaluate the role of ghrelin in the implantation process, pregnant females were injected with ghrelin or the antagonist starting from days 3 to 7 of gestation (periimplantation period). At day 18, females were killed and again the $\mathrm{nCL}$ in the ovaries as well as the number and weight of the fetuses found in the uterus was evaluated. The percentage of atrophied fetuses and $\mathrm{nCL} / \mathrm{nF}$ were also recorded. The initial body weight of females (pregnancy day 1) and weight gain during pregnancy were assessed, weighing dams at gestation days 7,14 , and 18. Moreover, after killing and gravid uterus removal on day 18, dams weight was assessed in order to subtract the litter weight from that of the mother.

\section{Confirmation of copulation}

The morning(s) after the introduction of an adult male mouse into the cage housing females, vaginal smears were collected and examined, and copulation was considered positive when a vaginal plug or spermatozoa in the vaginal smear were detected.

\section{Number of corpora lutea}

After females were killed at day 18, both ovaries were collected and placed in a capsule containing $2 \mathrm{ml}$ modified Tyrode's medium and the number of fresh corpora lutea/female was recorded under a stereoscopic magnifying glass. These corpora lutea are usually seen as notoriously round red-orange vascularized structures that protrude from the ovary surface. In previous experiments performed in our laboratory, we found that under control conditions, more than $80 \%$ of the females showed an equal $\mathrm{nCL}$ and $\mathrm{nF}$. That is why we consider this parameter as an acceptable sign of ovulation (Puechagut et al. 2012).

\section{Atrophied fetuses}

After females were killed at day 18 of gestation, the uterus was isolated and placed in a capsule containing $2 \mathrm{ml}$ modified Tyrode's medium and the amount and weight of the fetuses were evaluated. Fetuses clearly smaller than the normal ones with regard to their gestational age were counted as 'atrophied' (see Fig. 1; Luque et al. 2012). This parameter was calculated not only for each female (percentage of atrophied fetuses/female) but also for each treatment, recording the proportion of dams that exhibited some degree of fetal atrophy.

\section{Number of corpora lutea/number of fetuses}

Once the $\mathrm{nCL}$ and $\mathrm{nF}$ (including atrophied ones) were recorded at gestational day 18, an index between these two variables

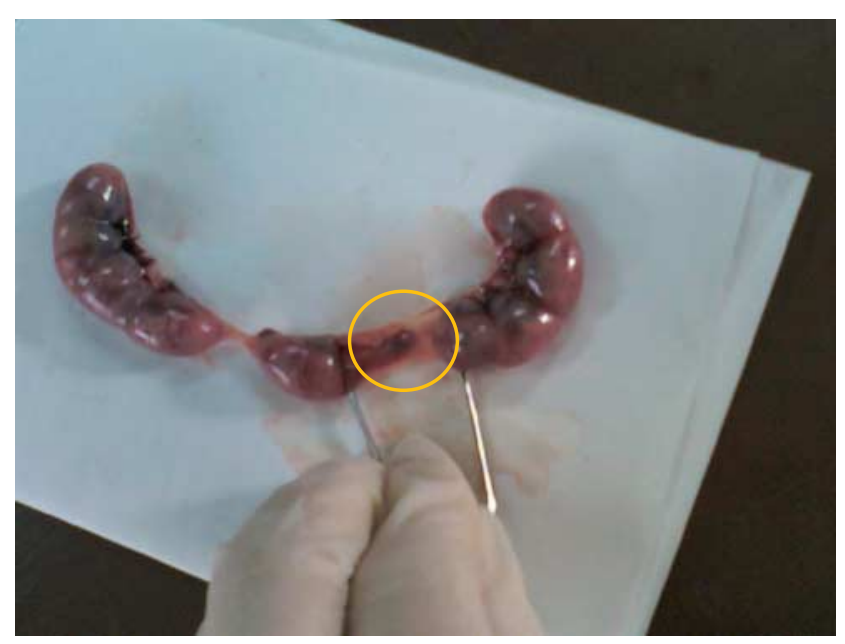

Figure 1 Atrophied mouse fetuses at day 18 of gestation (highlighted in yellow). The day of confirmation of copulation was considered day 1 .

was calculated using the following formula: $100-(\mathrm{nF} \times$ $100 / \mathrm{nCL}$ ). When we found a higher $\mathrm{nCL} / \mathrm{nF}$, we considered that some alterations had occurred in reproductive processes.

This parameter was calculated not only for each female, but also per treatment, i.e. recording the percentage of females/ treatment that exhibited more corpora lutea than fetuses (independent of the index value).

\section{Embryo developmental status}

Oviducts and uteri were obtained after $80 \mathrm{~h}$ of estimated ovulation from those females for which copulation had been confirmed and flushed in different capsules with $1.5 \mathrm{ml}$ modified Tyrode's medium. Under an inverted microscope, the number of oocytes or embryos, the percentage of fertilization (the number of oocytes with respect to the total amount of oocytes and embryos recovered), and the developmental status of the embryos were recorded. The results are expressed as the percentage of non-fertilized gametes and the percentage of embryos in each one of the two developmental stages: i) we considered as 'embryos developed up to the morula stage', to the sum of embryos of 2, 4, or more cells plus those in the morula stage and ii) 'blastocysts', to the sum of compact plus expanded plus hatched blastocysts (Luque et al. 2010).

\section{Statistical analysis}

The results are expressed as percentage or mean \pm S.E.M. Those represented as percentage (percentage of females with a higher $\mathrm{nCL} / \mathrm{nF}$, percentage of females with one or more atrophied fetuses, percentage of fertilization, percentage of embryos developed up to the morula stage, and percentage of blastocysts - represented in Figs 2 and 3, and 4) were analyzed by the $\chi^{2}$ test and those expressed as mean \pm s.E.M. (body weight gain during pregnancy, $\mathrm{nCL}$, litter size, weight of viable pups, $\mathrm{nCL} / \mathrm{nF}$, and atrophied fetuses - represented in Tables 1 and 2, Fig. 5) were analyzed using a one-way ANOVA with Fisher's LSD test as post-hoc comparison analysis. In all cases, $P$ values 


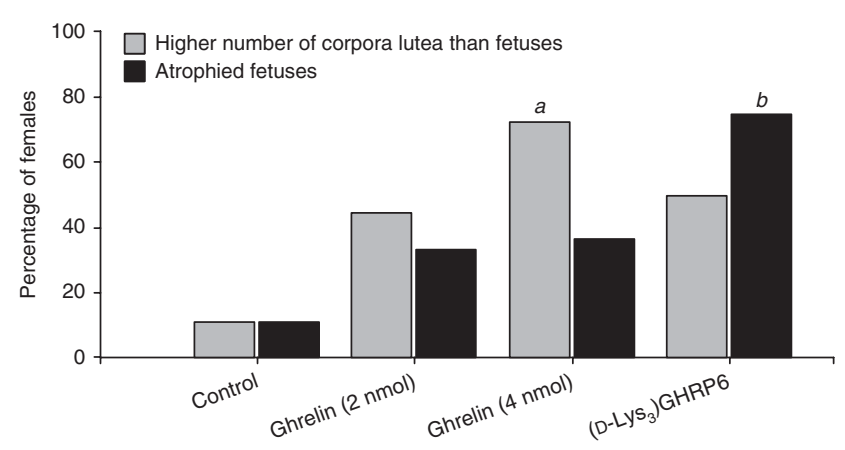

Figure 2 Percentage of females with a higher number of corpora lutea than fetuses (indicative of alterations in the reproductive process) or one or more atrophied fetuses at day 18 of pregnancy. Ghrelin ( 2 or 4 nmol/animal per day) or ghrelin antagonist (D-Lys ${ }_{3}$ GHRP6 ( $6 \mathrm{nmol} / \mathrm{animal}$ per day) were injected subcutaneously twice a day (half of the daily dose in each injection) starting from 1 week before until the day of mating confirmation, inclusive. Control females were injected with the vehicle (isotonic solution) in the same regimen. The results are expressed as the percentage of females that showed each feature. Fetal atrophy was considered as the finding of one or more fetuses remarkably smaller than the normal ones. The number of females in each group: control $=9$, ghrelin $(2 \mathrm{nmol})=9$, ghrelin $(4 \mathrm{nmol})=11$, and $\left(\mathrm{D}-\mathrm{Lys}_{3}\right) \mathrm{GHRP6}=8$. a, $P=0.0092$ vs control and b, $P=0.0134$ vs control.

under 0.05 were considered statistically significant. Statistical analyses were performed using Infostat 2000 (Infostat version 1.1, Group Infostat, FCA-UNC, Córdoba, Argentina).

\section{Results}

\section{Experiment 1}

When female mice received treatment starting from 7 to 9 days before copulation to $12 \mathrm{~h}$ after copulation, we found that on day 18 of gestation, neither ghrelin (in any dose) nor the antagonist modified the $\mathrm{nCL}$, litter size, or weight of viable pups (Table 1). In those females treated with ghrelin (both doses) or the antagonist, we did find an increase, although not significant, in the percentage of $\mathrm{nCL} / \mathrm{nF}$ with respect to control. A similar increasing tendency was detected in the percentage of atrophied fetuses, reaching statistical difference only in the group treated with the antagonist vs control. On the other hand, we detected an important increase in the percentages of treated females exhibiting a higher $\mathrm{nCL} / \mathrm{nF}$ or some degree of fetal atrophy with respect to controls (Fig. 2). These differences reached statistical significance for a higher $\mathrm{nCL} / \mathrm{nF}$ in females injected with ghrelin and for atrophied fetuses in mice treated with the antagonist.

\section{Experiment 2}

When treating females starting from the day of pharmacological induction of ovulation to the third day of pregnancy, we observed that the antagonist significantly diminished the fertilization index compared with the other groups. Additionally, both doses of ghrelin (in a dose-dependent manner) and the antagonist significantly delayed embryo development; this was demonstrated by the increase in the percentage of embryos that developed up to the morula stage and a decrease in the proportion of blastocysts (20-35\% reduction; Fig. 3).

It is important to mention that, as expected for the time elapsed from estimated ovulation to embryo retrieval, only $6.4 \%$ of total oocytes/embryos were obtained from oviductal flushing (93.6\% were obtained from uterus). As we did not find any differences in the developmental stage of the embryos retrieved from oviducts vs uterus or in the proportion of females exhibiting oocytes/embryos in the oviducts between experimental groups (results not shown), for statistical purposes, all retrieved oocytes/ embryos, independent of their origin, were considered together in each group.

\section{Experiment 3}

In females treated with ghrelin or the antagonist during the peri-implantation period (days 3-7 of pregnancy) and killed at day 18, we did not observe any differences in the litter size (including atrophied fetuses), but found a significant decrease in the weight of viable pups, in all treatments vs control. This reduction showed higher values in females treated with the highest dose of ghrelin

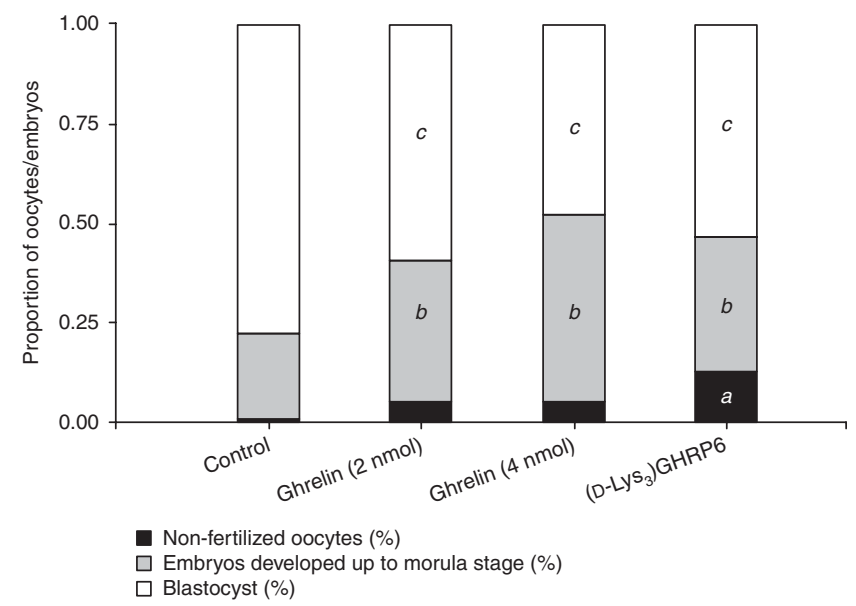

Figure 3 Proportion of non-fertilized oocytes and embryos that developed 'up to morula' stage (this category includes embryos of two to eight cells and morulae) or blastocyst stage (this category includes compact, expanded, and hatched blastocytes). Ghrelin (2 or $4 \mathrm{nmol} /$ animal per day) or ghrelin antagonist (D-Lys $\left.{ }_{3}\right)$ GHRP6 (6 nmol/animal per day) were injected subcutaneously twice a day (half of the daily dose at each injection) starting from the day of pharmacological superovulation induction to $80 \mathrm{~h}$ after estimated ovulation. Control females were injected with the vehicle (isotonic solution) in the same regimen. The total number of oocytes/embryos in each group: control $=103$, ghrelin $(2 \mathrm{nmol})=93$, ghrelin $(4 \mathrm{nmol})=92$, and (D-Lys ${ }_{3}$ ) GHRP6 $=96$. a, $P<0.05$ vs all other groups; $\mathrm{b}$ and $\mathrm{c}, \mathrm{P}<0.01$ vs control. 


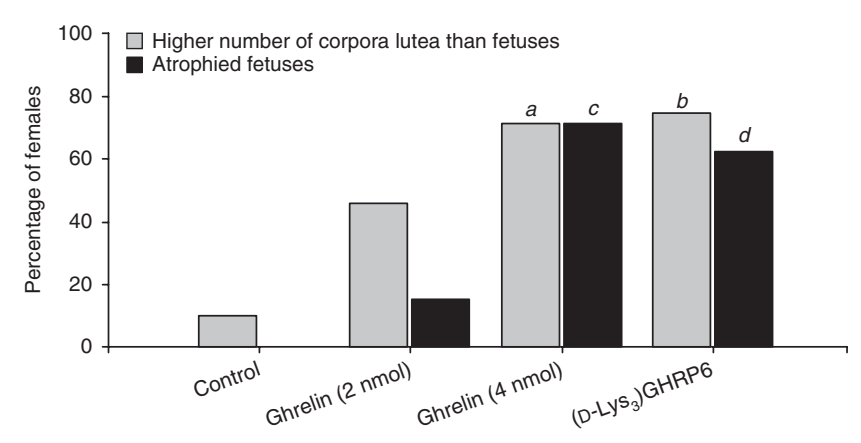

Figure 4 Percentage of females with a higher number of corpora lutea than fetuses (indicative of alterations in the reproductive process) or one or more atrophied fetuses at day 18 of pregnancy. Ghrelin (2 or $4 \mathrm{nmol} /$ animal per day) or ghrelin antagonist (D-Lys 3 )GHRP6 (6 nmol/ animal per day) were injected subcutaneously twice a day (half of the daily dose at each injection) starting from days 3 to 7 of gestation. Control females were injected with the vehicle (isotonic solution) in the same regimen. The results are expressed as the percentage of females showing each characteristic. Fetal atrophy was considered as the presence of one or more fetuses remarkably smaller than the normal ones. The number of females in each group: control $=10$, ghrelin $(2 \mathrm{nmol})=13$, ghrelin $(4 \mathrm{nmol})=7$, and $\left(D-\mathrm{Lys}_{3}\right) \mathrm{GHRP} 6=8$. $\mathrm{a}, \mathrm{b}, \mathrm{c}$ and $\mathrm{d}, \mathrm{P}<0.01$ vs control.

or with the antagonist (Table 2). In the former two groups, we also found an increase in the percentage of $\mathrm{nCL} / \mathrm{nF}$ or that of atrophied fetuses, although these differences reached statistical significance only for fetal atrophy (Table 2). Concordantly, when these two parameters were expressed in relation to the proportion of females with a higher $\mathrm{nCL} / \mathrm{nF}$ or some degree of fetal atrophy, we found that ghrelin ( $4 \mathrm{nmol} / \mathrm{animal}$ per day) and the antagonist significantly increased the percentage of females with both features when compared with control ones (Fig. 4).

Finally, when evaluating the increase in the weight of dams during pregnancy, we found that the highest dose of ghrelin and the antagonist significantly decreased the weight gain in females during pregnancy with respect to control or ghrelin $(2 \mathrm{nmol} /$ animal per day; Fig. 5). This phenomenon may be attributed to the smaller weight of the viable pups plus the increase in the percentage of atrophied fetuses (fetuses very small for their gestational age), as we found no differences in the body weight of females (at day 18) after gravid uterus removal ('dams weight gain', Fig. 5).

\section{Discussion}

The main objective of our study is to explore the physiological role of ghrelin in early gestational events, by means of an in vivo approach of hyperghrelinemia or inhibiting endogenous ghrelin effects. The results of this experimental design support the hypothesis that ghrelin modulates several gestational processes, including fertilization, early embryo development, and possibly implantation, exerting detrimental effects at high concentrations, at which this peptide may function as a food scarcity signal. Moreover, the administration of the antagonist provoked deleterious effects on these processes as well, suggesting that the physiological increase in plasma ghrelin concentrations during gestation would be necessary for a normal/optimal pregnancy progress. A number of new experiments are being currently developed in our laboratory in order to elucidate the cellular/molecular basis of such actions.

One of the major findings of our study was that not only ghrelin (in its highest dose) but also its antagonist significantly increased the percentage of $\mathrm{nCL} / \mathrm{nF}$ or that of atrophied fetuses and/or the percentages of females exhibiting a higher $\mathrm{nCL} / \mathrm{nF}$ or fetal atrophy in comparison to dams injected with the vehicle (experiments 1 and 3 ). As the first parameter was calculated as the amount of fetuses with respect to the $\mathrm{nCL}$ (suggestive of ovulation index), a smaller number of conceptuses may reflect alterations at diverse times of the process, i.e. at fertilization, early embryo development, and/or implantation. As females were treated during the periimplantation period in the third experiment (in which the percentage of $\mathrm{nCL} / \mathrm{nF}$ was more evident), the impairment of the fertilization process by ghrelin or the antagonist, at least in this experiment, is not a suitable explanation. A negative effect of the different treatments upon implantation and/or placenta formation/function seems to be more feasible; the results detected in experiment 3 for atrophied fetuses support

Table 1 Reproductive success of female mice injected with exogenous ghrelin or with (D-Lys S $_{3}$ GHRP6 (ghrelin antagonist) starting from 1 week before copulation.

\begin{tabular}{lcccc}
\hline Parameters & Control $(n=9)$ & $\begin{array}{c}\text { Ghrelin }(\mathbf{2} \mathbf{~ n m o l} / \mathbf{a n i m a l} \\
\text { per day) }(n=9)\end{array}$ & $\begin{array}{c}\text { Ghrelin (4 nmol/animal } \\
\text { per day) }(n=11)\end{array}$ & $\begin{array}{c}\text { (D-Lys }) \text { GHRP6 (6 nmol/ } \\
\text { animal per day) }(n=8)\end{array}$ \\
\hline Number of corpora lutea & $11.9 \pm 0.6$ & $12.7 \pm 0.8$ & $12.6 \pm 0.6$ & $13.3 \pm 0.7$ \\
Litter size & $11.7 \pm 0.7$ & $11.7 \pm 1.1$ & $11.3 \pm 0.7$ & $12.3 \pm 0.6$ \\
Weight of viable pups $(\mathrm{g})$ & $1.0 \pm 0.1$ & $1.1 \pm 0.0$ & $0.9 \pm 0.1$ & $1.0 \pm 0.1$ \\
nCL/nF (\%) & $2.2 \pm 2.2$ & $7.3 \pm 6.7$ & $9.8 \pm 5.4$ & $6.8 \pm 3.8$ \\
Atrophied fetuses (\%) & $0.1 \pm 0.1$ & $0.7 \pm 0.4$ & $0.6 \pm 0.3$ & $1.9 \pm 0.5^{*}$ \\
\hline
\end{tabular}

Ghrelin or its antagonist was injected subcutaneously twice a day (half of the daily dose in each injection). Control females were injected with the vehicle (isotonic solution) in the same regimen. The results are expressed as mean \pm S.E.M. $\mathrm{nCL} / \mathrm{nF}$, number of corpora lutea/number of fetuses, calculated as $100-(\mathrm{nF}$ at gestation day $18 \times 100 / \mathrm{nCL})$. When positive, this index was considered as a sign of alterations in reproductive processes. Atrophied fetuses were those remarkably smaller than the normal ones at gestation day 18 . $n$, number of females. ${ }^{*} P=0.0244$ vs control. 


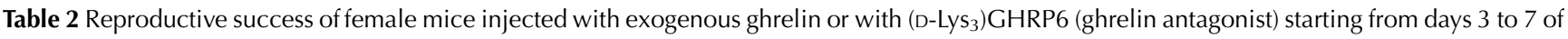
pregnancy (peri-implantation period).

\begin{tabular}{|c|c|c|c|c|}
\hline Parameters & Control $(n=12)$ & $\begin{array}{c}\text { Ghrelin (2 nmol/animal } \\
\text { per day) }(n=14)\end{array}$ & $\begin{array}{c}\text { Ghrelin }(4 \mathbf{n m o l} / \text { animal } \\
\text { per day })(n=9)\end{array}$ & $\begin{array}{l}\left(\text { D-Lys } \mathbf{s}_{3}\right) \text { GHRP6 }(6 \mathbf{~ n m o l} / \\
\text { animal per day) }(n=11)\end{array}$ \\
\hline Number of corpora lutea & $12.0 \pm 0.3$ & $13.5 \pm 0.8$ & $13.4 \pm 0.7$ & $13.1 \pm 0.7$ \\
\hline Litter size & $11.5 \pm 0.6$ & $12.2 \pm 1.1$ & $10.0 \pm 1.2$ & $12.3 \pm 0.9$ \\
\hline Weight of viable pups (g) & $1.0 \pm 0.3$ & $0.9 \pm 0.1^{*}$ & $0.8 \pm 0.1^{+}$ & $0.8 \pm 0.1^{\ddagger}$ \\
\hline $\mathrm{nCL} / \mathrm{nF}(\%)$ & $3.9 \pm 4.8$ & $5.8 \pm 8.6$ & $17.3 \pm 6.6$ & $6.7 \pm 4.0$ \\
\hline Atrophied fetuses (\%) & $0.0 \pm 0.0$ & $0.2 \pm 0.2$ & $1.3 \pm 0.4^{\S, \|}$ & $0.9 \pm 0.3^{\pi}$ \\
\hline
\end{tabular}

Ghrelin or its antagonist was injected subcutaneously twice a day (half of the daily dose in each injection). Control females were injected with the vehicle (isotonic solution) in the same regimen. The results are expressed as mean \pm s.E.M. $\mathrm{nCL} / \mathrm{nF}$, number of corpora lutea/number of fetuses, calculated as $100-(\mathrm{nF}$ at gestation day $18 \times 100 / \mathrm{nCL})$. When positive, this index was considered as a sign of alterations in reproductive processes. Atrophied fetuses were considered as those remarkably smaller than the normal ones at gestation day 18 . $n$, number of females. ${ }^{*, t, \neq} P=0.0488$ vs control; ${ }^{\$}, \| P=0.0020$ (ghrelin 4 and antagonist vs control); and ${ }^{\uparrow} P=0.0020$ (ghrelin 4 vs ghrelin ( 2 nmol)).

this hypothesis. In fact, these two parameters may be a reflection of altered placenta formation and/or function.

With regard to this fact, ghrelin has been proposed as one of the multiple signals involved in the crosstalk between the invading placenta and the endometrium (Tanaka et al. 2003, Tawadros et al. 2007). Tanaka et al. suggested that ghrelin may be involved in endometrial embryo receptivity and that it may influence pre-implantation embryo development, acting as a paracrine/autocrine factor. These authors performed an immunohistochemical analysis demonstrating that the strongest signal for ghrelin was found in the extravillous trophoblast cells from the first trimester placenta, which constitutes the frontier of invasion into the maternal endometrium. Moreover, they found that the in vitro addition of ghrelin to the culture medium stimulated the decidualization of human endometrial stromal cells obtained in the luteal phase (Tanaka et al. 2003). Similarly, other authors have reported that the in vitro culture of the placenta cell line JEG-3 with ghrelin $(100-1000 \mathrm{pg} / \mathrm{ml})$ for $48 \mathrm{~h}$ significantly stimulated cell proliferation and decreased apoptosis (Rak-Mardyla \& Gregoraszczuk 2010). These evidences are consistent with a dramatic increase in the peptide mRNA expression in the endometrium during early pregnancy and with the endometrial expression of the GHSR (GHSR1a) throughout the normal menstrual cycle and early pregnancy, demonstrated in vivo by Tanaka et al. (2003) Interestingly, these same authors found that in patients with ectopic pregnancies, ghrelin mRNA levels did not increase and ghrelin immunoreactivity was not detected in decidual cells.

All these evidences support the hypothesis that the increase in ghrelin secretion typical of early pregnancy contributes to endometrial decidualization and placenta formation. Therefore, it is possible that the alterations in this expected ghrelin raise (i.e. over increase or inhibition) exert deleterious effects on placentation.

Currently, investigations are being developed in our laboratory on the association between ghrelin and nitric oxide (NO) synthesis during the peri-implantation period and its effect on placental development. The placenta is a fast growing tissue that requires active blood supply and rapid vascular development endothelial $\mathrm{NO}$ synthases (iNOS and eNOS) are known to be involved in implantation regulation, placental formation, and placental nutrient transport to fetuses (Sladek et al. 1997, Kaufmann et al. 2003, Maul et al. 2003, Khan et al. 2012, Kulandalevu et al. 2012, Kusinski et al. 2012). On the other hand, in non-reproductive models, it has been demonstrated that ghrelin enhances NOS activity and consequently NO synthesis (Rodríguez-Pacheco et al. 2008, Morley et al. 2011, Sudar et al. 2011, Wang et al. 2012). All these evidences suggest that the detrimental effects on the implantation ratio observed in our study may be linked to an alteration in the NO synthesis exerted by abnormal ghrelin concentrations. Moreover, the significant decrease in fetal body weight at gestational day 18 may be related to a reduced nutrient transport ability of the placenta.

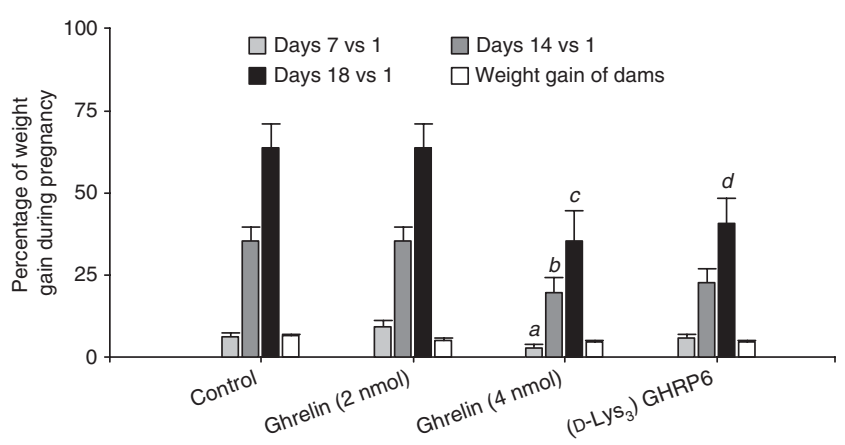

Figure 5 Weight gain of dams of females injected with ghrelin (2 or $4 \mathrm{nmol} /$ animal per day) or ghrelin antagonist (D-Lys 3$)$ GHRP6 $(6 \mathrm{nmol} /$ animal per day) starting from days 3 to 7 of gestation. Ghrelin and the antagonist were injected subcutaneously twice a day (half of the daily dose at each injection). Control females were injected with the vehicle (isotonic solution) in the same regimen. The results are expressed as the percentage of weight gain with respect to day 1 of gestation, calculated using the formula: (body weight $\times 100 /$ body weight at day 1 ) -100 . In addition, after killing and gravid uterus removal on day 18 , the weight of dams was assessed in order to subtract the litter weight from that of the mother ('dams weight gain'). The number of females in each group: control $=12$, ghrelin $(2 \mathrm{nmol})=14$, ghrelin $(4 \mathrm{nmol})=9$, and $\left(D-\right.$ Lys $\left._{3}\right)$ GHRP6 $=11$. a, $P=0.0392$ vs control and ghrelin $2 ; b, P=0.0292$ vs control and ghrelin 2; c and d, $P=0.0222$ vs control and ghrelin 2 . 
A special comment is worthy on the increase in the percentage of females exhibiting a higher $\mathrm{nCL} / \mathrm{nF}$ or atrophied fetuses observed in experiment 1, which included treatment with ghrelin or the antagonist starting from 1 week before the day of copulation, inclusive. This treatment did not comprise the implantation phase; in fact, it includes ovulation and presumably fertilization, as well as a fraction of the early embryo development period. In conclusion, the alterations found in this experiment at the implantation and/or fetal development processes may be linked to defects of other parameters such as oocyte quality or progesterone secretion by corpus luteum (Li et al. 2011, Rak-Mardyla et al. 2012). Regarding this issue, it has been reported that the corpora lutea secrete ghrelin, especially in the luteal phase and that this peptide significantly inhibits 3ß-hydroxysteroid dehydrogenase activity and progesterone secretion (Rak-Mardyla et al. 2012). In agreement with these findings, results in human obtained in an assisted reproduction center have demonstrated that the follicular fluid concentrations of ghrelin negatively correlated with progesterone values (Li et al. 2011). More importantly, these authors informed that follicular fluid ghrelin negatively correlated with the embryo cleavage rate and number of viable embryos at day 3, explained by alterations in oocyte quality ( $\mathrm{Li}$ et al. 2011). Some experiments are being currently performed in our laboratory, destined to evaluate, in our experimental conditions, oocyte morphology, maturation, and spontaneous activation.

In our study, we found that the treatment of pregnant females with ghrelin or its antagonist during the early embryo developmental period (starting from hCG injection to $80 \mathrm{~h}$ after estimated ovulation) significantly delayed embryo development to blastocyst in a dosedependent manner. A study of the in vitro effects of different doses of ghrelin on ovine oocyte maturation and embryo development has been recently published (Wang et al. 2013). While the smaller doses of ghrelin $(50 \mathrm{ng} / \mathrm{ml})$ increased blastocyst rates and the total number of cells per blastocyst (compared with 0 or $10 \mathrm{ng} / \mathrm{ml}$ ), a higher dose $(250 \mathrm{ng} / \mathrm{ml})$ decreased these parameters, suggesting that there is an 'appropriate' concentration of the peptide that promotes blastocyst formation (Wang et al. 2013). This is consistent with the results obtained in our study, in which, the addition of not only ghrelin but also the antagonist altered embryo progress. Other authors have also performed in vitro experiments and observed that ghrelin significantly diminished the progression of two-cell embryos to blastocysts, and that coincubation with ghrelin and the same antagonist used in our study reversed these deleterious effects (Kawamura et al. 2003). To our knowledge, this is the first study that evaluates the in vivo effects of administration of ghrelin and its antagonist on embryo development.

In our study, in this same experiment, the antagonist significantly diminished the fertilization index. To our knowledge, such an effect has not been informed in any of the previous studies. In vitro experiments are being currently performed in our laboratory in order to elucidate these aspects.

It is important to notice that the results obtained in the former experiment were for females with pharmacologically induced superovulation. It has been reported that this treatment may alter the oocyte quality/maturity and consequently embryo development (Ertzeid \& Storeng 2001). With this in mind, the actual effects of ghrelin or the antagonist during early embryo development in naturally ovulated females are still unknown.

As mentioned before, in experiment 3, on day 18, we found a significant decrease in the weight of fetuses obtained from dams treated with ghrelin or the antagonist during the peri-implantation period. This may explain the reduction in the weight gain of dams during pregnancy (in groups ghrelin $(4 \mathrm{nmol})$ and antagonist), as there were no differences in the body weight of these females after removal of the gravid uterus. Indeed, the reduction in the weight gain of dams was maximal in ghrelin $(4 \mathrm{nmol})$ group, which is the one that presented the smallest litter size and weight of pups. Concordantly, in previous studies carried out in our laboratory with a ghrelin analog called hexarelin, we found that this substance, when administered during the first week of pregnancy, significantly increased the percentage of $\mathrm{nCL} / \mathrm{nF}$ and tended to reduce the litter size (Luque et al. 2010, Puechagut et al. 2012).

It has been reported that ghrelin administered to pregnant rats easily crosses through the placenta to the fetus blood and amniotic fluid and that this substance stimulates epithelial cell proliferation in cultures (Nakahara et al. 2006). Besides, several authors have informed that the administration of ghrelin to pregnant rats (starting from pregnancy days 1 to 11 or from day 14 or 15 to delivery) increases the weight of pups at delivery (Hayashida et al. 2002, Fernández-Fernández et al. 2005, Nakahara et al. 2006). This fact has been confirmed by our team in mice treated with $4 \mathrm{nmol}$ ghrelin during the whole gestation period ( $\mathrm{P}$ Torres, E Luque and A C Martini, unpublished observations). Nevertheless, in this study, ghrelin was administered only during the peri-implantation period, in which it exerted detrimental effects on fetal weight. Nonetheless, not only ghrelin but also the antagonist exerted these negative actions, suggesting that the peri-implantation period is a critical stage in which 'adequate' ghrelin concentrations would be necessary for placenta formation and/or functioning. As mentioned above, it is well known that a functionally altered placenta may provoke a reduction in fetus development and weight gain (Kusinski et al. 2012); this is probably the explanation of our results, as the percentages of $\mathrm{nCL} / \mathrm{nF}$ and atrophied fetuses were higher in the three experimental groups, especially when using 4 nmol ghrelin.

Finally, although so far descriptive, our in vivo study supports the hypothesis that during early gestation, 
'adequate' ghrelin concentrations would be necessary to guarantee normal/optimal pregnancy progression. Certainly, additional experiments will provide further information about the cellular/molecular basis of these results.

\section{Declaration of interest}

The authors declare that there is no conflict of interest that could be perceived as prejudicing the impartiality of the research reported.

\section{Funding}

This study was supported by grants from CONICET (PIP 20102012 number 11420090100126CO, 918/10), SECyT-UNC (05/H127, 162/12), and SECYT-UNLaR (CICyT 051/12).

\section{Author contribution statement}

R D Ruiz, M Fiol de Cuneo and A C Martini are established investigators of the Consejo Nacional de Investigaciones Científicas y Tecnológicas (CONICET). M Fiol de Cuneo and A C Martini are members of INICSA, CONICET- Universidad Nacional de Córdoba, Universidad Nacional de Córdoba, Santa Rosa 1085, X5000ESU Córdoba, Argentina

\section{Acknowledgements}

The authors are grateful to Grupo Pilar-GEPSA for generously providing the pelleted feed for our animals.

\section{References}

Barreiro ML \& Tena-Sempere M 2004 Ghrelin and reproduction: a novel signal linking energy status and fertility? Molecular and Cellular Endocrinology 226 1-9. (doi:10.1016/j.mce.2004.07.015)

Barreiro ML, Gaytán F, Caminos JE, Pinilla L, Casanueva FF, Aguilar E, Dieguez C \& Tena-Sempere M 2002 Cellular location and hormonal regulation of ghrelin expression in rat testis. Biology of Reproduction $\mathbf{6 7}$ 1768-1776. (doi:10.1095/biolreprod.102.006965)

Bertoldi ML, Luque EM, Carlini VP, Vincenti LM, Stutz G, Santillán ME, Ruiz RD, Fiol de Cuneo M \& Martini AC 2011 Inhibitory effects of ghrelin on sexual behavior: role of the peptide in the receptivity reduction induced by food restriction in mice. Hormone and Metabolic Research 43 494-499. (doi:10.1055/s-0031-1277228)

Caminos JE, Tena-Sempere M, Gaytán F, Sánchez-Criado JE, Barreiro ML, Nogueiras R, Casanueva FF, Aguilar E \& Dieguez C 2003 Expression of ghrelin in the cyclic and pregnant rat ovary. Endocrinology 144 1594-1602. (doi:10.1210/en.2002-221058)

Du C, Li H, Cao G, Xilingaowa, Wang C \& Li C 2010 Expression of the orexigenic peptide ghrelin and the type 1a growth hormone secretagogue receptor in sheep oocytes and pre-implantation embryos produced in vitro. Reproduction in Domestic Animals 45 92-98. (doi:10.1111/ j.1439-0531.2008.01259.x)

Ertzeid G \& Storeng R 2001 The impact of ovarian stimulation on implantation and fetal development in mice. Human Reproduction $\mathbf{1 6}$ 221-225. (doi:10.1093/humrep/16.2.221)

Fernández-Fernández R, Tena-Sempere M, Aguilar E \& Pinilla L 2004 Ghrelin effects on gonadotropin secretion in male and female rats. Neuroscience Letters 362 103-107. (doi:10.1016/j.neulet.2004.03.003)

Fernández-Fernández R, Navarro VM, Barreiro ML, Vigo EM, Tovar $S$, Sirotkin AV, Casanueva FF, Aguilar E, Dieguez C, Pinilla L et al. 2005
Effects of chronic hyperghrelinemia on puberty onset and pregnancy outcome in the rat. Endocrinology 146 3018-3025. (doi:10.1210/ en.2004-1622)

Fernández-Fernández R, Martini AC, Navarro VM, Castellano JM, Dieguez C, Aguilar E, Pinilla L \& Tena-Sempere M 2006 Novel signals for the integration of energy balance and reproduction. Molecular and Cellular Endocrinology 254-255 127-132. (doi:10.1016/j.mce.2006.04.026)

Fuglsang J, Skjaerbaek C, Espelund U, Frystyk J, Fisker S, Flyvbjerg A \& Ovesen P 2005 Ghrelin and its relationship to growth hormones during normal pregnancy. Clinical Endocrinology 62 554-559. (doi:10.1111/ j.1365-2265.2005.02257.x)

García MC, López M, Álvarez CV, Casanueva F, Tena-Sempere M \& Dieguez C 2007 Role of ghrelin in reproduction. Reproduction 133 531-540. (doi:10.1530/REP-06-0249)

Gaytán F, Morales C, Barreiro ML, Jeffery P, Chopin LK, Herington AC, Casanueva FF, Aguilar E, Dieguez C \& Tena-Sempere M 2005 Expression of growth hormone secretagogue receptor type 1a, the functional ghrelin receptor, in human ovarian surface epithelium, mullerian duct derivatives, and ovarian tumors. Journal of Clinical Endocrinology and Metabolism 90 1798-1804. (doi:10.1210/jc.2004-1532)

Govoni N, Parmeggiani A, Galeati G, Penazzi P, De lasio R, Pagotto U, Pasquali R, Tamanini C \& Seren E 2007 Acyl ghrelin and metabolic hormones in pregnant and lactating sows. Reproduction in Domestic Animals 42 39-43. (doi:10.1111/j.1439-0531.2006.00722.x)

Gualillo O, Caminos J, Blanco M, García-Caballero T, Kojima M, Kangawa K, Dieguez C \& Casanueva F 2001 Ghrelin, a novel placental-derived hormone. Endocrinology 142 788-794.

Harrison JL, Adam CL, Brown YA, Wallace JM, Aitken RP, Lea RG \& Miller DW 2007 An immunohistochemical study of the localization and developmental expression of ghrelin and its functional receptor in the ovine placenta. Reproductive Biology and Endocrinology 525. (doi:10.1186/1477-7827-5-25)

Hayashida T, Nakahara K, Mondal MS, Date Y, Nakazato M, Kojima M, Kangawa K \& Murakami N 2002 Ghrelin in neonatal rats: distribution in stomach and its possible role. Journal of Endocrinology 173 239-245. (doi:10.1677/joe.0.1730239)

Kaufmann P, Black S \& Huppertz B 2003 Endovascular trophoblast invasion: implications for the pathogenesis of intrauterine growth retardation and preeclampsia. Biology of Reproduction 69 1-7. (doi:10.1095/biolreprod.102.014977)

Kawamura K, Sato N, Fukuda J, Kodama H, Kumagai J, Tanikawa H, Nakamura A, Honda Y, Sato T \& Tanaka T 2003 Ghrelin inhibits the development of mouse preimplantation embryos in vitro. Endocrinology 144 2623-2633. (doi:10.1210/en.2003-0033)

Khan H, Kusakebe KT, Wakitani S, Hiyama M, Takeshita A \& Kiso Y 2012 Expression and localization of NO synthase isoenzymes (iNOS and eNOS) in development of the rabbit placenta. Journal of Reproduction and Development 58 231-236. (doi:10.1262/jrd.11-128T)

Kojima M \& Kangawa K 2005 Ghrelin: structure and function. Physiological Reviews 85 495-522. (doi:10.1152/physrev.00012.2004)

Kojima M, Hosoda H, Date Y, Nakazato M, Matsuo H \& Kangawa K 1999 Ghrelin is a growth-hormone acylated peptide from stomach. Nature $\mathbf{4 0 2}$ 656-666. (doi:10.1038/45230)

Kojima M, Hosoda H, Matsuo H \& Kangawa K 2001 Ghrelin: discovery of the natural endogenous ligand for the growth hormone secretagogue receptor. Trends in Endocrinology and Metabolism 12 118-122. (doi:10.1016/S1043-2760(00)00362-3)

Kulandalevu S, Whiteley KJ, Qu D, Mu J, Bainbridge SA \& Adamson SL 2012 Endothelial nitric oxide synthase deficiency reduces uterine blood flow, spiral artery elongation, and placental oxygenation in pregnant mice. Hypertension 60 231-238. (doi:10.1161/HYPERTENSIONAHA. 111.187559)

Kusinski LC, Stanley JL, Dilworth MR, Hirt CJ, Andersson IJ, Renshall LJ, Baker BC, Baker PN, Sibley CP, Wareing M et al. 2012 eNOS knockout mouse as a model of fetal growth restriction with an impaired uterine artery function and placental transport phenotype. American Journal of Physiology. Regulatory, Integrative and Comparative Physiology 303 R86-R93. (doi:10.1152/ajpregu.00600.2011)

Li L, Ferin M, Sauer MV \& Lobo RA 2011 Serum and follicular fluid ghrelin levels negatively reflect human oocyte quality and in vitro embryo development. Fertility and Sterility 96 1116-1120. (doi:10.1016/ j.fertnstert.2011.08.017) 
Luque EM, Carlini V, Vincenti LM, Puechagut P, Stutz G, Santillán ME, Ruiz RD, Martini AC \& Fiol de Cuneo M 2010 Effects of hexarelin (ghrelin analogue) on fertilization and pre-postnatal development of mice. Reproduction, Fertility, and Development 22 926-938. (doi:10.1071/RD09231)

Luque EM, Vincenti LM, Stutz G, Santillán ME, Ruiz RD, Fiol de Cuneo M \& Martini AC 2012 Ghrelin modulates fertilization, early embryo development and implantation. Endocrine Abstracts 29 OC6.2.

Maul H, Longo M, Saade GR \& Garfield RE 2003 Nitric oxide and its role during pregnancy: from ovulation to delivery. Current Pharmaceutical Design 9 359-380. (doi:10.2174/1381612033391784)

Morley JE, Farr SA, Sell RL, Hileman SM \& Banks WA 2011 Nitric oxide is a central component in neuropeptide regulation apetite. Peptides $\mathbf{3 2}$ 776-780. (doi:10.1016/j.peptides.2010.12.015)

Nakahara K, Nakagawa M, Baba Y, Sato M, Toshinai K, Date Y, Nakazato M, Kojima M, Miyazato M, Kaiya $\mathbf{H}$ et al. 2006 Maternal ghrelin plays an important role in rat fetal development during pregnancy. Endocrinology 147 1333-1342. (doi:10.1210/en.2005-0708)

Palik E, Baranyi E, Melczer Z, Audikovszky M, Szocs A, Winkler G \& Cseh K 2007 Elevated serum acylated (biologically active) ghrelin and resistin levels associate with pregnancy-induced weight gain and insulin resistance. Diabetes Research and Clinical Practice 76 351-357. (doi:10.1016/j.diabres.2006.09.005)

Puechagut P, Martini AC, Stutz G, Santillán ME, Fiol de Cuneo M, Ruiz RD \& Vincenti LM 2012 Reproductive performance and fertility in male and female adult mice chronically treated with hexarelin. Reproduction, Fertility, and Development 24 451-460. (doi:10.1071/RD11009)

Rak-Mardyla A \& Gregoraszczuk E 2010 Effect of ghrelin on proliferation, apoptosis and secretion of progesterone and hCG in the placental JEG-3 cell line. Reproductive Biology 10 159-165. (doi:10.1016/S1642431X(12)60058-8)

Rak-Mardyla A, Gregoraszczuk EL, Karpeta A \& Duda M 2012 Expression of ghrelin and the ghrelin receptor in different stages of porcine corpus luteum development and the inhibitory effects of ghrelin on progesterone secretion, $3 \beta$-hydroxysteroid dehydrogenase ( $3 \beta$-honestly significant difference (HSD)) activity and protein secretion. Theriogenology 77 1505-1512. (doi:10.1016/j.theriogenology.2011.11.017)

Rodríguez-Pacheco F, Luque RM, Tena-Sempere $M$, Malagón MM \& Castaño JP 2008 Ghrelin induces growth hormone secretion via nitric oxide/cGMP signaling pathway. Journal of Neuroendocrinology 20 406-412. (doi:10.1111/j.1365-2826.2008.01645.x)

Schneider JE 2004 Energy balance and reproduction. Physiology \& Behavior 81 289-317. (doi:10.1016/j.physbeh.2004.02.007)

Shibata K, Hosoda H, Kojima M, Kangawa K, Makino Y, Makino I, Kawarabayashi T, Futagami K \& Gomita Y 2004 Regulation of ghrelin secretion during pregnancy and lactation in the rat: possible involvement of hypothalamus. Peptides 25 279-287. (doi:10.1016/j.peptides.2004.01.011)

Sladek SM, Magness RR \& Conrad KP 1997 Nitric oxide and pregnancy. American Journal of Physiology 272 R441-R463.
Sudar E, Dobutovic B, Soskic S, Mandusic V, Zakula Z, Misirkic M, Vucicevic L, Janjetovic K, Trajkovic V, Mikhailidis DP et al. 2011 Regulation of inducible nitric oxide synthase activity/expression in rat heart from ghrelin-treated rats. Journal of Physiology and Biochemistry 67 195-204. (doi:10.1007/s13105-010-0063-1)

Sun Y, Garcia JM \& Smith RG 2007 Ghrelin and growth hormone secretagogue receptor expression in mice during aging. Endocrinology 148 1323-1329.

Tanaka K, Minoura H, Isobe T, Yonaha H, Kawato H, Wang DF, Yoshida T, Kojima M, Kangawa K \& Toyoda N 2003 Ghrelin is involved in the decidualization of human endometrial stromal cells. Journal of Clinical Endocrinology and Metabolism 88 2335-2340. (doi:10.1210/jc.2002021024)

Tawadros N, Salamonsen LA, Dimitriadis E \& Chen C 2007 Facilitation of decidualization by locally produced ghrelin in the human endometrium. Molecular Human Reproduction 13 483-489. (doi:10.1093/molehr/ gam029)

Tena-Sempere $\mathbf{M}$ 2008a Ghrelin and reproduction: ghrelin as novel regulator of the gonadotropic axis. Vitamins and Hormones 77 285-300.

Tena-Sempere $\mathbf{M} 2008 \mathrm{~b}$ Ghrelin as a pleiotrophic modulator of gonadal function and reproduction. Nature Clinical Practice. Endocrinology \& Metabolism 4 666-674. (doi:10.1038/ncpendmet1003)

Wang X, Liang L \& Du L 2007 The effects of intrauterine undernutrition on pancreas ghrelin and insulin expression in neonate rats. Journal of Endocrinology 194 121-129. (doi:10.1677/JOE-07-0057)

Wang D, Wang H, Luo P, Hwang A, Sun D, Wang Y, Zhang Z, Liu NN, Wang S, Li C et al. 2012 Effects of ghrelin on homocysteine induced dysfunction and inflammatory response in rat cardiac microvascular endothelial cells. Cell Biology International 36 511-517. (doi:10.1042/ CBI20110235)

Wang Z, Lin P \& Yu S 2013 Effects of ghrelin on developmental competence and gene expression of in vitro fertilized ovine embryos. Theriogenology 79 695-701. (doi:10.1016/j.theriogenology.2012.11.026)

Wei W, Qi X, Reed J, Ceci J, Wang HQ, Wang G, Englander EW \& Greeley JH Jr 2006 Effect of chronic hyperghrelinemia on ingestive action of ghrelin. American journal of Physiology - Regulatory, Integrative and Comparative Physiology 290 R803-R808.

Zhang K, Wei HX, Zhang YH, Wang SH, Li Y, Dai YP \& Li N 2007 Effects of ghrelin on in vitro development of porcine in vitro fertilized and parthenogenetic embryos. Journal of Reproduction and Development 53 647-653. (doi:10.1262/jrd.18140)

Received 5 March 2014

First decision 17 March 2014

Revised manuscript received 30 April 2014

Accepted 12 May 2014 